\title{
Zenker's diverticulum peroral endoscopic myotomy using a scissors-type knife
}

Zenker's diverticulum is a rare anatomic defect characterized by herniation of the hypopharyngeal mucosa between the inferior aspect of the inferior constrictor muscle and the cricopharyngeus muscle. Most patients are elderly and present with symptoms of dysphagia, regurgitation, chronic cough, aspiration, and weight loss [1]. The treatment of symptomatic Zenker's diverticulum has evolved from open surgical approaches to minimally invasive endoscopic procedures [2].

Peroral endoscopic myotomy for Zenker's diverticulum (Z-POEM) is an endoscopic technique where the principles of submucosal endoscopy are followed. The procedure is composed of a mucosal incision, submucosal tunneling, septotomy, and mucosal closure [3]. This procedure has the potential to reduce the risk of perforation and mediastinitis [4]. Herein, we report an older patient with a symptomatic Zenker's diverticulum who was treated with Z-POEM using a scissors-type endoscopic submucosal dissection (ESD) knife, the SB Knife. The potential benefits of the SB Knife include that: submucosal tissue and vessels can be coagulated and cut simultaneously; full-thickness myotomy can be performed accurately and efficiently; and rates of perforation may be lower with the grasping of muscle during myotomy [5].

An 84-year-old woman with a past medical history of breast cancer was referred with increasing dysphagia and weight loss. A barium study confirmed a $1.5-\mathrm{cm}$ Zenker's diverticulum and the decision was made to proceed with Z-POEM.

The procedure was performed with the patient under general anesthesia. The diverticulum was at 9 o'clock at the level of the upper esophageal sphincter with the endoscope in the resting position ( Fig.1a). Submucosal injection was performed at the posterior aspect of the septum using a mixed solution of normal saline and methylene blue. A mucosal in-
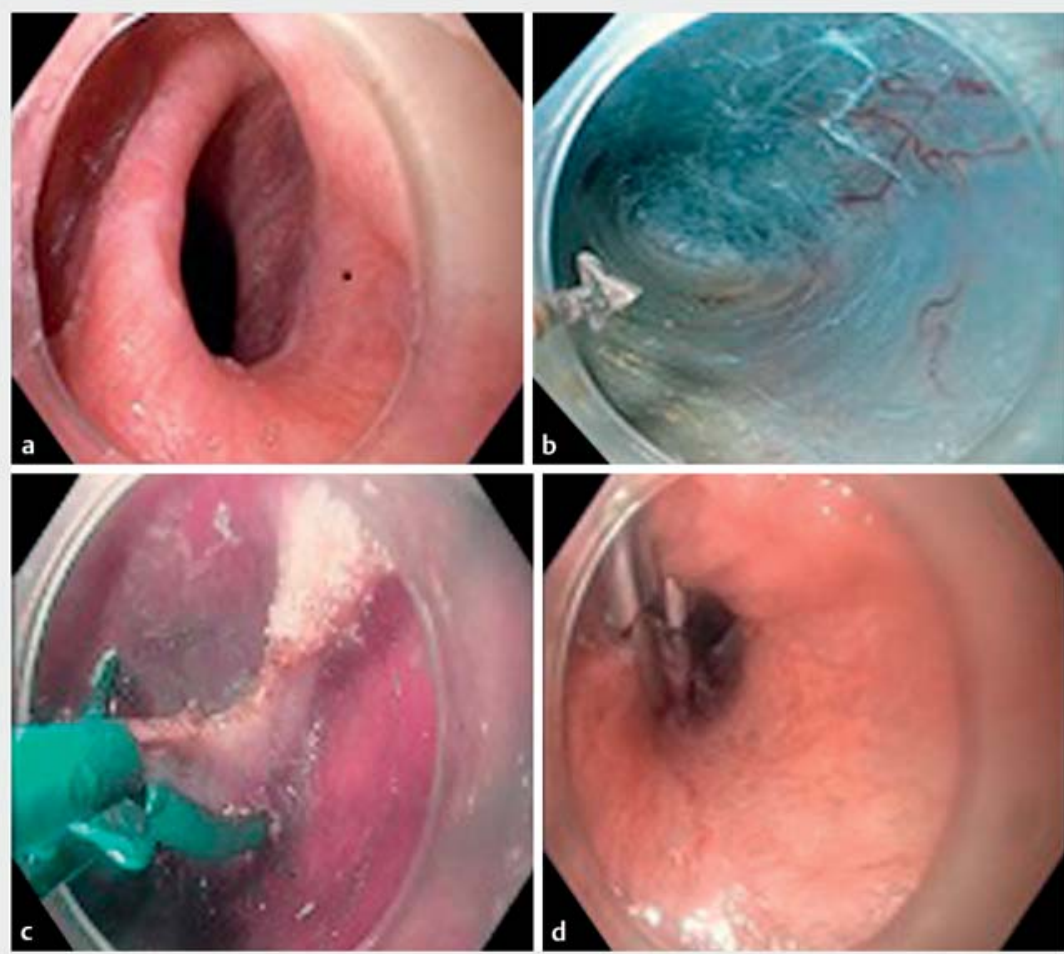

- Fig. 1 Images of the peroral endoscopic myotomy (POEM) procedure for a Zenker's diverticulum showing: a the diverticulum at the level of the upper esophageal sphincter in the resting position; $\mathbf{b}$ the finished tunnel with complete exposure of the septum; c septotomy being performed using a standard SB Knife; $\mathbf{d}$ secure closure of the mucosal incision using endoclips.

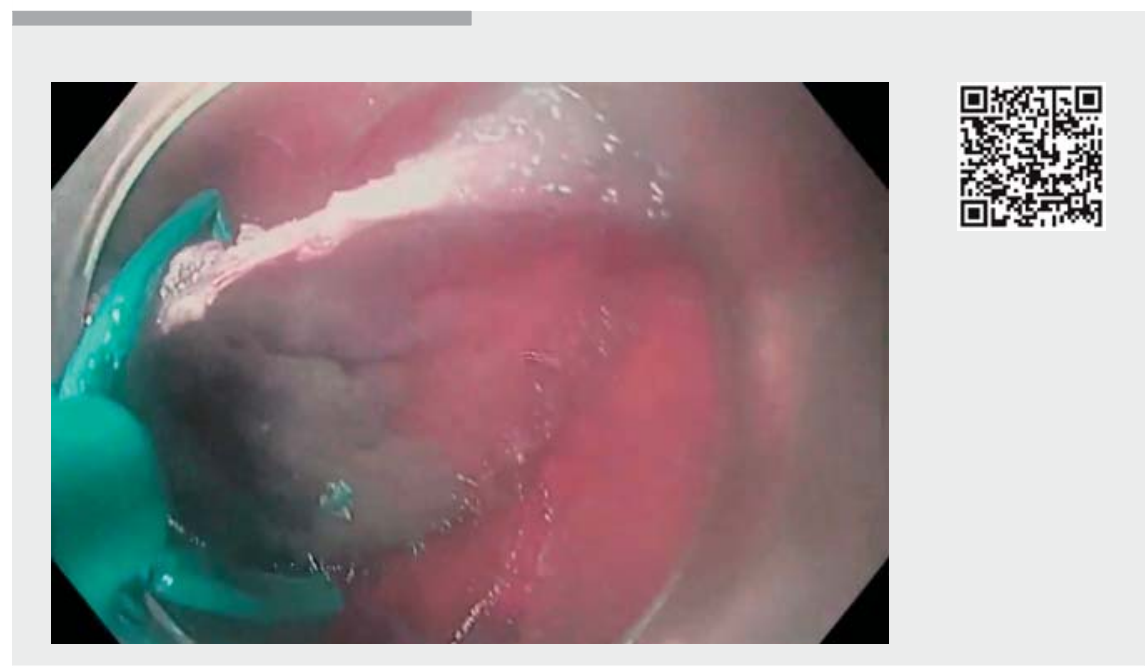

$\checkmark$ Video 1 Procedure of peroral endoscopic myotomy for a Zenker's diverticulum using a scissors-type ESD knife. 
cision was made, followed by submucosal dissection with a triangle-tip knife (spray coagulation mode; effect 2 and $40 \mathrm{~W}$ ). The muscular layer of the septum was exposed. Submucosal dissection was performed on the luminal side and the diverticular side until the tunnel was distal to the base of the Zenker's diverticulum, the dissection being carried out for a total

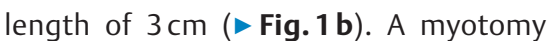
was performed using a standard SB knife, with a working length of $1.8 \mathrm{~mm}$ and maximal opening diameter of $2.6 \mathrm{~mm}$, with cautery setting of Endocut $Q$ current; effect 3 , interval 1 , and duration 1 . A complete myotomy was performed after complete exposure of the septum ( $\triangleright$ Fig.1 c). The mucosal incision was closed with endoclips ( Fig.1d; - Video 1).

There were no immediate complications. The patient was admitted overnight, and an esophagogram performed the next day showed no leakage. There is a risk of foreign body sensation with clip placement, but we have a preference for the placement of clips with short stalks to avoid this issue. At follow-up, the patient remained asymptomatic 90 days after undergoing Z-POEM.

Endoscopy_UCTN_Code_TTT_1AO_2AN

\section{Competing interests}

\section{None}

The authors

Seyma Bahsi ${ }^{1}$, Nigar Rustemova ${ }^{1}$, Kia Vosoughi², Yervant Ichkhanian², Tossapol Kerdsirichairat ${ }^{2}$, Juliana Yang ${ }^{2}$, Mouen A. Khashab ${ }^{2}$

1 Department of Internal Medicine, Acibadem Mehmet Ali Aydınlar University Faculty of Medicine, Istanbul, Turkey

2 Division of Gastroenterology and Hepatology, Johns Hopkins Medical Institution, Baltimore, Maryland, USA

Corresponding author

Mouen A. Khashab, MD

Division of Gastroenterology, Department of Medicine, Johns Hopkins Hospital, 1800 Orleans St, Suite 7125 B, Baltimore, MD 21205, USA

Fax: +1-443-683-8335

Mkhasha1@jhmi.edu

\section{References}

[1] Ciuc D, Birla R, Panaitescu E et al. Zenker diverticulum treatment: endoscopic or surgical? Chirurgia 2018; 113: 234-243

[2] Ferreira LE, Simmons DT, Baron TH et al. Zenker's diverticula: pathophysiology, clinical presentation, and flexible endoscopic management. Dis Esophagus 2008; 21: 1-8
[3] Khashab MA, Benias PC, Swanstrom LL et al. Endoscopic myotomy for foregut motility disorders. Gastroenterology 2018; 154: $1901-1910$

[4] Li QL, Chen WF, Zhang XC et al. Submucosal tunneling endoscopic septum division: a novel technique for treating Zenker's diverticulum. Gastroenterology 2016; 151: $1071-1074$

[5] Fortinsky KJ, Toshitaka S, Samarasena JB et al. Early experience using a scissors-type knife in peroral endoscopic myotomy. Gastrointest Endosc 2018; 87: AB572

\section{Bibliography}

DOI https://doi.org/10.1055/a-0881-2774

Published online: 2.5.2019

Endoscopy 2019; 51: E231-E232

(c) Georg Thieme Verlag KG

Stuttgart · New York

ISSN 0013-726X

\section{ENDOSCOPY E-VIDEOS \\ https://eref.thieme.de/e-videos}

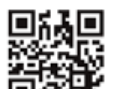

Endoscopy E-Videos is a free access online section, reporting on interesting cases and new

techniques in gastroenterological endoscopy. All papers include a high quality video and all contributions are freely accessible online.

This section has its own submission website at https://mc.manuscriptcentral.com/e-videos 